\title{
The effect of repetition of objects and object names on free recall*
}

\author{
PETER L. DERKS $\dagger$ and JEAN E. DUNMAN $\dagger \dagger$ \\ College of William and Mary, Williamsburg, Virginia 23185
}

\begin{abstract}
Repeated presentation of objects or object names increased their probability or .eca. i. Obierts were recalled better than object names, although the significance was borderline. Presentation of objects and their names separately in a sequence resulted in recall at least as good as the repetition of an object. When asked to recall how the items had been presented, Ss made more errors on presentation conditions of names than of objects. These results support an imaginal-verbal dual code interpretation of memory for objects and object names and indicate differences in the codes.
\end{abstract}

Repeated presentation of an item increases the probability that it will appear in free recall (Waugh, 1963). "Concrete" items are also more likely to be recalled than more abstract items. Bevan and Steger (1971), for example, found that objects were better recalled than photographs and photographs were better recalled than the names of the objects. The advantage that concrete objects show over abstract items in recall has been attributed to imaginal and verbal "dual codes" (Bower, 1970; Paivio, 1969). When an object is presented it will probably also be processed or coded with its name, but if just a name is presented it is less likely to produce an image. The dual coding of the concrete object improves recall, perhaps through the implicit repetition. One purpose of the present study was to examine the relation between repetition and concreteness.

A second purpose was to examine the relation between objects and their names. Recall for objects and their names which were both presented in the set of items to be recalled was compared with recall for repeated objects and recall for repeated names. If the interaction between an object and its name is simply additive, recall for an object-name presentation should be some average of repeated objects and repeated names. If there is some mutual facilitation between the "dual codes," then recall for an object-name presentation will be as good, or even better, than for the simple repetition of the most effective of the two forms. Paivio and Csapo (1973) have performed a similar experiment using pictures and names. Their rationale was very similar and is described more thoroughly in that paper.

A further measure of storage, used by Bevan and Stegar (1971), is the recall output order of presentation conditions. They found that correct recall of a category of items was also reflected in the output orders. Objects were best remembered, tended to appear first and last in recall, and predominated throughout recall. These results suggested a greater overall availability of concrete items

*T. Michael Bauer assisted in earlier pilot studies and Ly nn S. Schulz contributed help ful suggestions.

tRequests for reprints and further information should be sent to Peter L. Derks, Department of Psychology, College of William and Mary, Williamsburg, Virginia 23185.

††Jean E. Dunman is currently at the School of Education, University of Virginia, Charlottesville, Virginia 22204. rather than a higher priority in recall. A third purpose of the present study, then, was to compare the effects of concreteness and repetition on output order.

\section{EXPERIMENT I}

\section{Method}

Fifteen male and 15 female undergraduates at the College of William and Mary were used in this experiment. The experimental sessions took about $20 \mathrm{~min}$, and the Ss received \$1 for participation. Twenty-four familiar objects and their respective names served as the stimulus items. Twenty-one of these items were taken from Bevan and Steger (1971). The other three were chosen from Carroll, Davies, and Richman (1971) within the frequency range of the items used by Bevan and Steger. The three additional items were ball, box, and rock. Each object name was printed in black on a $5 \times 8$ in. white index card. The letters were approximately $1.50 \mathrm{in}$. tall and $0.25 \mathrm{in}$. thick to ensure legibility.

Each S was told that a series of 24 items would be presented as both objects and object names. Four of the items would appear once as objects (O-1), four once as object names $(\mathrm{N}-1)$, four as repeated objects (O-2), four as repeated object names $(\mathrm{N}-2)$, four objects repeated as their object names (O-N), and four object names repeated as their corresponding objects (N-O). The presentation duration was approximately $5 \mathrm{sec}$.

The Ss were instructed that they would have to write as many of the items as they could recall. Each $S$ was presented with a unique order of items so that the type of presentation was counterbalanced for each item as was the order of presentation of repetition types. Since a series of pilot studies indicated that primacy was a more important determiner of recall than recency in the procedure used here, all 24 different items were presented followed by the scheduled repetitions, a total of 40 presentations. Furthermore, a 5-min mathematical problem-solving task immediately followed the presentation of stimulus items to reduce recency effects (Postman \& Phillips, 1965). At the end of $5 \mathrm{~min}$ of monitored problem solving, $S$ was instructed to write the names of all the stimulus items he could remember.

\section{Results \\ Even though all the objects were familiar and high in imagery, they differed greatly in probability of recall. (Recall over all conditions ranged from 93\% for the items "apple" and "pencil" to $43 \%$ for "radio.") Since presentation of the items was counterbalanced by conditions, these differences could not be reflected in recall of specific presentation conditions.}


Table 1

Proportion Correctly Recalled (R) and Output Order Data; Average Recall Location (ARL), Average Initial Recall Location (Initial), Number of First Responses (First), Average Final Recall Location (Final), and the Number of Last Responses (Last) for Each Condition of Experiment I

\begin{tabular}{lcrcccc}
\hline & R & ARL & Initial & First & Final & Last \\
\hline N-1 & .492 & 10.7 & 7.5 & 1 & 15.6 & 5 \\
N-2 & .758 & 9.8 & 5.2 & 7 & 14.3 & 6 \\
N-0 & .833 & 8.5 & 4.1 & 4 & 12.2 & 2 \\
O-1 & .583 & 10.9 & 6.5 & 7 & 15.8 & 9 \\
O-2 & .817 & 9.4 & 4.7 & 6 & 13.8 & 5 \\
O-N & .908 & 8.1 & 3.6 & 5 & 13.1 & 3 \\
\hline
\end{tabular}

Table 1 shows the proportion recalled for each presentation condition along with various output order data. Repetition improved recall, $F(2,58)=54.24$, $\mathrm{p}<.001$. The repeated items $(\mathrm{N}-2$ and $\mathrm{O}-2)$ were recalled significantly more often than the single presentations $(\mathrm{N}-1$ and $\mathrm{O}-1), \mathrm{t}(29)=7.88, \mathrm{p}<.01$. The repetition of objects by object names $(\mathrm{O}-\mathrm{N})$ or vice versa (N-O) also produced significantly better recall than the repetition condition where concrete and abstract stimuli were not mixed $(\mathrm{N}-2$ and $0-2), \mathrm{t}(29)=2.67, \mathrm{p}<.05$.

The presentation of an object first yielded significantly higher recall than the presentation of a word first, $F(1,29)=5.74, p<.025$. The interaction was not significant, $F(2,58)=0.09$. The objects $(0-1$ and $\mathrm{O}-2)$ were recalled better than the names (N-1 and N-2), $t(29)=1.82$. This is not a significant difference, however, when the significance levels are adjusted for number of comparisons by Dunn's procedure (Kirk, 1968). The trend of these results supports Paivio and Csapo with respect to relative difficulty of conditions. The absolute recall in their study was lower, however, since they used a 96 -item list and the present study used only 40 items.

The output order data was based on the average recall location (ARL) for each condition for each S. For example, if two items were recalled from Condition N-1 and appeared 4th and 12th in recall, ARL would be 8 . Weighted means were used in cases with no output. This order of report data showed that repeated items were recalled slightly but significantly earlier than nonrepeated items, $F(2,58)=6.86, p<.01$. The presentation of either a word or an object first was not reflected in ARL, however, $F(1,29)=0.11$, nor was there an interaction between an object or a word presented first and repetition, $\mathrm{F}(2,58)=0.25$.

Both the significant advantage of repeated items and the small and insignificant difference between objects and names in ARL were reflected in the average initial recall location (initial) and the average final recall location (final) of the presentation conditions. Well-recalled conditions were remembered relatively early but did not persist in recall. Finally, there was no significant difference among presentation conditions reported first, $\chi^{2}(5)=5.2$, or last, $\chi^{2}(5)=6.0$. The lack of general availability of objects in recall does not replicate the results of Bevan and Steger. Their observations, however, were based only on samples of the data. Sampling was necessary in their study since there were many Ss who recalled nothing from some categories. The best $S$ in their study recalled 14 of 21 items. The average recall in the present study was 17.6 of 24 items and only four Ss omitted a cagegory entirely. Three Ss omitted N-1 and one omitted $0-1$. This generally good performance also probably helped reduce all differences between object and name recall.

\section{EXPERIMENT II}

The superior recall of names repeated as objects and especially objects repeated as names over simple repetition of objects argues for the dual coding system. In fact, the advantage of $\mathrm{O}-\mathrm{N}$ over all other conditions, including $\mathrm{N}-\mathrm{O}$, was large enough to be suspicious, especially since Paivio and Csapo reported no such difference. Therefore, a second experiment was conducted, partly as a general replication.

In Experiment II, the Ss were also asked to recall how the different items had been presented to supply more information on how items were stored for recall (Tulving, 1972; Ghatala, Levin, \& Wilder, 1973). For example, the advantage of repeated items in recall could be a result of an increased number of representations in memory. If so, some recall of a repeated item might result from the retrieval of just one of those representations. Although the recall of this single presentation would be enough for a correct response, $S$ would remember it as having occurred only once. A correct response, and improved recall of a repeated item, would result from only part of the potential information. The effect of frequency on recall would be to increase the probability of contacting one instance of the item in memory.

If recall for the presentation conditions is relatively accurate, however, then recall of the items themselves must be based on more than just a simple representation in memory. The $\mathrm{S}$ would have information not only about the name of the item, but when and how it had been presented. Every presentation of an item would be better recalled for each repetition. Therefore, a second purpose of Experiment II was to determine the quality of the information that results in correct recall of repeated objects and names.

\section{Method}

Thirty new Ss were selected from the same population, and the apparatus and procedure were the same as Experiment I, with one addition. At the end of the 5-min mathematics task, Ss were instructed to recall the items, and also how they had been presented. This additional recall requirement had not been mentioned previously, so the Ss were again told the six different presentation conditions. Three Ss failed to follow these instructions and were replaced.

\section{Results}

The percent correct for each stimulus item ranged from $97 \%$ for "pencil" to $40 \%$ for "fork." The percent 
Table 2

Proportion Correctly Recalled (R), Output Order Data; Average Recall Location (ARL), Average Initial Recall Location (Initial), Number of First Responses (First), Average Final Recall Location (Final), Number of Last Responses (Last), and Proportion of Recalled Items With the Presentation Condition Correctly Recalled (CR) for Each Condition of Experiment II

\begin{tabular}{cccccccc}
\hline & $\mathrm{R}$ & ARL & Initial & First & Final & Last & CR \\
\hline N-1 & .517 & 10.2 & 7.5 & 0 & 15.3 & 6 & .803 \\
N-2 & .725 & 9.3 & 4.7 & 9 & 14.1 & 6 & .708 \\
N-0 & .842 & 8.7 & 4.7 & 8 & 12.9 & 6 & .850 \\
O-1 & .550 & 10.4 & 6.9 & 2 & 15.3 & 3 & .933 \\
O-2 & .817 & 9.2 & 4.9 & 5 & 13.5 & 3 & .947 \\
O-N & .817 & 8.1 & 4.1 & 6 & 12.5 & 6 & .708 \\
\hline
\end{tabular}

recall by item for Experiments I and II correlated $\mathrm{r}(22)$ $=.78, \mathrm{p}<.001$. The recall differences among the items were not only large but also consistent.

Table 2 shows the percent recalled for each presentation condition along with the output order data for Experiment II. The proportion of presentation conditions correctly recalled, given that the item was recalled (CR), is also included.

The recall proportions for Experiment II are similar to those of Experiment I except for O-N, which was reduced by .091 . Repetition again improved recall, $\mathrm{F}(2,58)=34.02, \mathrm{p}<.001$. The repeated items $(\mathrm{N}-2$ and 0-2) were recalled significantly more often than the single presentations $(\mathrm{N}-1$ and $0-1), \mathrm{t}(29)=5.64$, $\mathrm{p}<.001$. Mixed repetition $(\mathrm{O}-\mathrm{N}$ and $\mathrm{N}-\mathrm{O})$ was recalled slightly better than unmixed ( $\mathrm{N}-2$ and $\mathrm{O}-2)$, but with the decreased recall of $\mathrm{O}-\mathrm{N}$ the difference was not significant, $t(29)=1.82$. Since the additional response requirements did not affect the recall of any other presentation condition, it appears that the recall of O-N in Experiment I was spuriously good. Still, at worst, recall of mixed repetition is equivalent to the recall of simple repetition at best.

The decline of $\mathrm{O}-\mathrm{N}$ recall also reduced the advantage of presenting an object first, $F(1,29)=0.93$. The interaction was not significant, $F(2,58)=1.08$. As in Experiment I, objects (O-1 and O-2) were recalled better than names (N-1 and N-2), but the effect was again short of significance, $t(29)=1.68$. Still, the consistency of the advantage in these two experiments supports other studies such as those cited by Paivio $(1969,1971)$ and indicates that objects are more likely to be represented in free recall than are names.

The various output order data for Experiment II agree with the same information from Experiment I. The greatest difference between comparable measures for the two sets is less than a full position. Repetition again produced earlier ARL, $\mathrm{F}(2,58)=4.59, \mathrm{p}<.05$. The object-object name distinction had no effect by itself, $F(1,29)=0.17$, or in interaction with repetition, $F(2,58)$ $=0.20$.

Thus, as in Experiment I, there was no difference in output between objects and names while repeated items were recalled relatively early but did not persist in recall. In fact, in Experiment II, the advantage of repeated names over not repeated names produced a significant difference in presentation conditions recalled first, $\chi^{2}(5)$ $=12.00, \mathrm{p}<.05$. There was no difference in conditions reported last, however, $\chi^{2}(5)=2.4$.

The presentation conditions of the items were accurately recalled even though the Ss were unaware this information would be requested. If the Ss had simply guessed, CR would have been about .167 and overall CR was .822 . Even the order of the object-object name presentations were well remembered. If order is disregarded, CR for N-O increases from .850 to .944 , and for $\mathrm{O}-\mathrm{N}$, the increase is from .708 to .864 . Either way, repetition alone was not a significant factor in CR: regarding order, $\mathrm{F}(2,58)=1.86$; disregarding order, $F(2,58)=1.51$. The other effects are presented with regard to order as those Fs were smallest.

Presentation conditions with names first were not as well identified as conditions with objects first, $F(1,29)=$ $5.27, \mathrm{p}<.05$. The interaction with repetition was also significant, $F(2,58)=7.90, p<.001$. The presentation conditions of objects (O-1 and $0-2)$ were better recalled than those of names $(\mathrm{N}-1$ and $\mathrm{N}-2), \mathrm{t}(29)=4.14$, $p<.01$. Most errors in the recall of how a name was presented were in the report of repetitions (Hintzman, Block, \& Summers, 1973). An item presented as N-2 was identified as an N-1 presentation on an average of .238 of the recalls of $\mathrm{N}-2$ presentations. An O-2 was confused with $0-1$ just once in the whole experiment, or on about $1 \%$ of the recalls. Finally, $\mathrm{N}-\mathrm{O}$ and $\mathrm{O}-\mathrm{N}$ were never reported as $\mathrm{N}-1$ or $\mathrm{N}-2$ but only as $\mathrm{O}-1, \mathrm{O}-2$, or in reversed order.

\section{DISCUSSION}

Repetition resulted in improved and earlier recall for names and objects. The mechanisms, however, seem to have been different. The accurate recall of presentation conditions showed that multiple records of an item are available for free recall. Some of the advantage in free recall of repeated names, however, came from the recall of just a single instance of a repeated presentation.

Repeated objects were also better recalled, but the S could almost always report that the repetition had occurred. The item seemed to have become more available as a unified collection of events, rather than more frequently represented by independent traces. The advantage of a unified collection of events might be to enhance the discriminability of the item and increase its resistance to interference from other items (Lesgold \& Goldman, 1973). Distinctiveness has been defined as a variable different from association and suggested as a contributor to the recall of images (Bower, 1972; Saltz, 1971). 
When an object was repeated as an object name or vice versa ( $\mathrm{O}-\mathrm{N}$ and $\mathrm{N}-\mathrm{O})$, the object presentation served two functions in supporting recall. First, the name was more likely to be recalled as part of the repetition than if the name was simply presented twice. Second, when the name was not recalled as such, the item could still appear in free recall as an object presentation. These results lend further support to the concept of dual coding for verbal and visual material, and suggest that different mechanisms, multiple traces for verbal material and increased discrimination for imagery, are differentially important in the effect of repetition for the two codes.

\section{REFERENCES}

Bevan, W., \& Steger, J. A. Free recall and abstractness of stimuli. Science, 1971, 172, 597-599.

Bower, G. H. Analysis of a mnemonic device. American Scientist, 1970, 58, 496-510.

Carroll, J. B., Davies, P., \& Richman, B. Word frequency book. New York: Houghton Mifflin and American Heritage, 1971.

Ghatala, E. S., Levin, J. R., \& Wilder, L. Apparent frequency of words and pictures as a function of pronunciation and imagery. Journal of Verbal Learning \& Verbal Behavior, 1973, 12, 85-90.
Hintzman, D. L., Block, R. A., \& Summers, J. J. Modality tags and memory for repetitions: Locus of the spacing effect. Journal of Verbal Learning \& Verbal Behavior, 1973, 12, 229-238.

Kirk, R. E. Experimental design: Procedures for the behavioral sciences. Belmont, California: Brooks/Cole, 1968.

Lesgold, A. M., \& Goldman, S. R. Encoding uniqueness and the imagery mnemonic in associative learning. Journal of Verbal Learning \& Verbal Beahvior, 1973, 12, 193-202.

Paivio, A. Mental imagery in associative learning and memory. Psychological Review, 1969, 76, 241-263.

Paivio, A. Imagery and verbal processes. New York: Holt, Rinehart, \& Winston, 1971.

Paivio, A., \& Csapo, K. Picture superiority in free recall: Imagery or dual coding? Cognitive Psychology, 1973, 5, 176-206.

Postman, L., \& Phillips, L. W. Short-term temporal changes in free recall. Quarterly Journal of Experimental Psychology, $1965,17,132-138$.

Saltz, E. The cognitive bases of human learning. Homewood, $\mathrm{nl}$ : Dorsey, 1971.

Tulving, E. Episodic and semantic memory. In E. Tulving and W. Donaldson (Eds.), Organization and memory. New York: Academic Press, 1972.

Waugh, N. C. Immediate memory as a function of repetition. Journal of Verbal Learning \& Verbal Behavior, 1963, 2, 107-112.

(Received for publication February 11, 1974.) 